\title{
A Study on the Factors Influencing the Rate of Learning and Adoption of Technologies by the Livestock Farmers of Ramanathapuram District, India
}

\author{
T.A. Vijayalingam ${ }^{1 *}$, N.V. Rajesh ${ }^{1}$, S. Ilavarasan ${ }^{1}$, \\ R. Venkataramanan ${ }^{2}$ and D. Ramasamy ${ }^{3}$
}
${ }^{1}$ Veterinary University Training and Research Centre, Tamilnadu Veterinary and Animal Sciences University, Ramanathapuram, Tamil Nadu, India
${ }^{2}$ Post Graduate Research Institute in Animal Sciences, Tamilnadu Veterinary and Animal Sciences University, Kancheepuram, Tamil Nadu, India
${ }^{3}$ Director of Extension Education, Tamilnadu Veterinary and Animal Sciences University, Madhavaram Milk Colony, Chennai, Tamil Nadu, India

*Corresponding author

\begin{tabular}{|l|}
\hline K e y w o r d s \\
$\begin{array}{l}\text { Livestock Farmers, } \\
\text { Training impact, } \\
\text { Rates of adoption }\end{array}$ \\
\hline Article Info \\
\hline $\begin{array}{l}\text { Accepted: } \\
\text { 07 October } 2019 \\
\text { Available Online: } \\
10 \text { November } 2019\end{array}$ \\
\hline
\end{tabular}

This paper analyses the factors that are affecting the rate of learning interest and adoption of newer technologies extended through Veterinary University Training and Research Centre, Ramanathapuram, a recently established (June 2013) constituent unit of TANUVAS, by the farmers of Ramanathapuram district. The present study was carried out for a period of 2 years (June 2016 to May 2018). The source of database included, 1) the total number of beneficiaries enrolled themselves for the training, 2) the total turn outs out of the enrolled 3) the total missed outs after their enrolment for the training 4) total beneficiaries attended the training programme without any prior enrolment but as a result of advertisement in regional newspaper, state level magazines, Reliance voice talk messages, TANUVAS mobile apps etc., 5) data on rate of adoption of technologies by different categories of trainees towards new farm establishment and improvement in the already established farms. The analysis revealed that there was a significant improvement in their knowledge after attending two days on-campus training on various farming enterprises. The adoption level was found to be higher among the farmers attending training on country chicken farming, followed by sheep and goat farming. Although female participants showed 100\% interest in attending training, none of them started new farm in this district. The adoption level is poor in case of dairy farming, due to huge initial investment and non-availability of green fodder in this district. Overall, young and lesser educated male participants were eager in adopting technologies by starting new farm after attending the training. 


\section{Introduction}

Almost all countries in the world deliver some type of extension services to help rural people to augment their agricultural productivity and improve their living standard (Wambural et $a l .$, 2012). Extension is responsible for serving about one billion small scale farmers in the world (Davis et al., 2010). This has led to the increased need and opportunity for investigating the effectiveness of extension services in various parts of the world. Also, this situation stimulates the need for new approaches to promote the transition of new innovations into concrete benefits to poor farmers in developing countries (Hellin, 2012). Other issues affecting efficiency of the extension system include poor organizational structure, poor administrative and institutional structure, lack of clientele involvement in the planning process, and untimely provision of extension services (Campbell, 1999). Research has been conducted to address these issues (Campbell, 1999), but there is insufficient research on the role of the clients (farmers) in the effectiveness of the extension system.

Abdullah and Samah (2013) pointed out that weak perception of technology, low education of farmers, disorganization, and limited knowledge among extension workers are some of the factors that affect the success of extension trainings. Because extension deals with people (Moris, 1991), there is a need to understand these people's perceptions about what extension programs deliver to them. Therefore, there is a need to know the extent to which farmers want the animal husbandry and other allied educational activities in their areas. The role of extension is to empower farmers and enable them to identify and analyze their animal husbandry and allied problems, so they are able to make correct decisions (Kimaro et al., 2010). The role of farmers' preferences in adoption decisions has received very limited attention in adoption studies conducted (Adesina and Baidu-Forson, 1995). Moreover, the importance of this study relies on the fact that farmers' perceptions of technologies and knowledge delivered through extension education programs can be used in explaining farmers' adoption decisions (Adesina and Baidu-Forson, 1995). Therefore, the problem statement for this study is: How does a farmer's perception knowledge through extension training programs affect his or her participation in these animal husbandry activities by starting new farms in Ramanathapuram district.

The concern is not only with the learning and securing adoption of a particular improved practice, but also it can successfully bring about certain changes in the outlook and attitude of farmers and thereby making them capable of rendering farming tasks more effectively and efficiently; continually seek means of improving farming enterprise (Halakatti, 2007). Farmers' training equips farmers with improved practices, which help them to adopt and practice effectively. The skills acquired through training helps the recipient to carry out an improved practice effectively and efficiently. If farmers are well trained in new practices, they may need minimal technical advice and outside backup support (Quddus, 2011). According to FAO (2012), farmers' training aims at communicating information, knowledge and skills, replacing old attitudes by new ones, exchanging opinions and experiences and reducing the amount of perceived complexity in a technology thereby creating a desired change.

This study therefore, focused to assess as to whether the training of farmers on improved animal husbandry practices by the Veterinary University Training and Research Centre, Ramanathapuram has brought changes in the targeted farmers in adopting the improved animal husbandry practices. It is also to 
understand the rate of adoption among different category of people in Ramanathapuram district. The findings of this study has formed a basis to follow better disseminating technologies by this centre in future to enhance the adoption of improved animal husbandry practices by the trained farmers of this district.

\section{Materials and Methods}

This paper analyses the impact and adoption rates of extension activities being carried out through Veterinary University Training and Research Centre, Ramanathapuram, a recently established (June2013) constituent unit of Tamilnadu Veterinary and Animal Sciences University, by the ultimate beneficiaries, the livestock farming community of Ramanathapuram district, Tamil Nadu, India. The main objectives of the centre are 1) to satisfy the needs of farmers and entrepreneurs of Ramanathapuram district in various animal husbandry activities to improve their living standards, 2) to impart on and off campus training on livestock and poultry farming to the needy farmers, 3) to conduct various awareness programme, village adoption programme, on farm trials, front line demonstration programmes for the farming community, 4) to carry out rural development programmes related to animal husbandry in coordination with various government agencies and NGOs for the upliftment of rural people, 5) dissemination of knowledge to needy people through various technological teaching aids, 6) Caters the needs of the livestock and poultry farmers through training, consultancy services in setting up of new farms, offering project reports etc., The present study was carried out for a period of 2 years (June 2016 to May 2018). The database included, 1) the total number of beneficiaries enrolled themselves for the training, 2) the total turn outs, out of the enrolled 3) the total missed outs after their enrolment for the training 4) total beneficiaries attended the training programme without any prior enrolment but as a result of advertisement in regional newspaper, state level magazines, Reliance voice messages, TANUVAS mobile apps etc., 5) data on the rate of adoption of technologies by different categories of trainees by the ways of establishing new farms and improvement in the management of the already established farms.

The databases collected were compared, tabulated and statistically analyzed (Snedecor and Cochran, 1994) using Chi-Square test to study and understand the rates of adoption by different categories of trainees / farmers attending trainings.

\section{Results and Discussion}

Ahmed (2015) highlighted the factors affecting farmers' learning index as the number of family members, large animal ownership, degree of leadership, tendency to change and community of the people. This study included the diversified factors like sex, age, community, education, employment and monthly income status of the trainee that create the difference in adoption level.

\section{Impact study of Sex and Adoption Rates}

The present study revealed that female participants were punctual in attending training without fail after their enrolment. It was found to be $100 \%$ rather than the male participants (59.90\%) after giving application for the training. In case of female participants their interest was higher towards country chicken and dairy unlike other farming activities. Although 54 Nos of female participants showed interest in attending training, none of them started new farm enterprise. However among the 437 male participants, 60 Nos of them started new farm in this district. The level of farming adoption 
was directly proportional to the number of turned out in each enterprise, stating higher level of adoption towards country chicken farming followed by sheep and goat, dairy and Japanese quail. Although women play an important role in animal husbandry and men consider their opinions to some extent, women took more time to be convinced to adopt the recommendations. They needed to consult or get approval from their male head of family. This indicates that final decision making in this region was vested with men. The similar concept of Quisumbing and Pandolfelli (2009) was in opinion to the statement.

\section{Impact study of age and adoption rates}

Age wise analysis showed that older age group (>50yrs) showed $92.60 \%$ turn outs in attending trainings after their enrolment for the training programmes, middle age group (30-50yrs) $65.49 \%$ and young age group (18$30 y r s)$ was $45.46 \%$. It indicated the higher responsibility of the older age people and the easy taking of the youngsters. The participants who turned out directly for the training was almost higher in case of age group (18-30yrs) and (31-50yrs) as compared to older age group (>50yrs) and the turned out was 33. It was a fact that advertising media like TV channel, mobile apps and newspaper had covered wider age group from 18-50yrs. However limited accessibility of media communication technological tools for older age group (>50yrs) and less inclination and time for them in noting advertisement had result in lesser turned outs for the training programme with direct participation.

Farmer age and education correlate among themselves. Farmer who were more than 50 years, almost illiterate or who had attended school only through the primary level. In this impact study older age group almost attended training after given application. However lesser turned out in direct participation, due to lack in usage of technology. But the older age group who can pitfall on education level upto $10^{\text {th }}$ standard take higher responsibility in attending training. The adoption level of older group to start new farm was comparatively lower than younger age group except for poultry farming, in which adoption level is higher might be due to easy managemental measures and lesser work burden for the older group. However in case of younger group, adoption level is higher due to energetic nature and application of innovative ideas, easy accessibility and adoption of new technology. The middle age group falls between younger and older age group, in adopting new farms. Overall the older age group to start new farm was poor in this district, might be attributed due to poor income source, unemployed status, lack of assistance from banking sectors, unawareness about the government implemented scheme. This was justified with the same concept of (Pannel, 2006; Gedigoklu, 2012) stated raising awareness of innovation especially among the receptive groups towards perception and willingness to adopt technologies.

\section{Impact study of community and adoption rates}

Community wise analysis during the study period showed that $48.81 \%$ turned out in SC/ST category and $66.16 \%$ in other communities. The participants turned out for the training with or without prior enrolment were higher in case of other communities rather than SC/ST category. Since the majority population of this district comes under the category of $\mathrm{BC}, \mathrm{MBC}$ and $\mathrm{DNC}$ as compared to $\mathrm{SC} / \mathrm{ST}$ category. Hence community wise analysis was directly proportionate to the community of this district in case of attending training conducted. Adoption level to start new farm is comparatively equal for both category. However there is a higher adoption rate for poultry farming in SC/ST category, 
might be attributed due to government implemented poultry development scheme in the rural backyard.

\section{Educational qualification wise analysis}

Educational qualification wise analysis revealed that farmers with lesser education up to $10^{\text {th }}$ standard $(74.78 \%)$ showed more responsibility in attending and benefitted out of the training programmes rather than the degree holders $(56.15 \%)$. This might be because of the higher rates of opportunities available in the livestock and poultry sectors which could have conferred confidence to the less qualified personnel which was not the case in other private or public sectors. The less turn outs among the degree holders might be due to their busy schedule of work or employment or studies. The adoption level to start new farm in the district also seems to higher in case of lesser educated group (upto $10^{\text {th }}$ standard and diploma holder), who were eager to seek self-employment to self sustained their life. Overall, the participants with lesser education upto $10^{\text {th }}$ standard and degree holders turned out in more numbers, both in the category of attended training with and without prior enrolment as compared to $12^{\text {th }}$ standard and diploma holder. But in case of adoption lesser educated group (upto $10^{\text {th }}$ and diploma holder) hold higher grade as compared to degree holder towards attending training.

\section{Employment status wise analysis}

The analysis also showed that $80 \%$ (8 out of 10) of the enrolled retired, government employees turned out the trainings compared to the self-employed personnel, where the turnout was $64.33 \%$ (202 out of 314) and persons working in private sectors $54.55 \%$ (48 out of 88). The higher rates of turnouts among the retired personnel might be due to their interest in seeking alternate job to keep themselves engaged and found themselves always useful and active where as the interest evinced by the self-employed people might be because of their nature to have additional incomes. On the other hand the lesser response from the people working in private sectors might be due to their tight, busy schedule of their regular work.

\section{Monthly income status wise analysis}

The people from different monthly income strata were also found to be responded differently. The monthly income of the people and the attitude towards approaching for the training programme was found to be inversely proportional (120 enrolment among $>$ Rs.10000/Month and 292 enrolment among $<$ Rs.10000/Month). But the rate of attending the training programme was directly proportional to the monthly income of the people $(72.5 \%$ among >Rs.10000/Month group and 58.5\% among <Rs.10000/Month group) (Fig. 1 to 6$)$.

\section{Analysis of participants attended training with prior enrolment}

The analysis also revealed the fact that, there was a wide variation in the number of enrolment for training on different enterprises. Although lesser farmers had given application for training on dairy farming (70 Nos), their attendance was $75.71 \%(53 / 70)$, for country chicken it was $63.82 \%(97 / 152)$, for sheep and goat $59.85 \%$ (79/132), Japanese quail $53.33 \%$ (19/30) and for turkey $66.67 \%$ (8/12).

There was no turn out for the training on rabbit farming. However, analysis of the enrolments and the attendance particulars of the training showed that, there is more demand for the training on country chicken farming $37.60 \%$ (97/258), followed by sheep and goat $30.62 \%$ (79/258), dairy cattle $20.54 \%$ (53/258), Japanese quail $7.34 \%(19 / 258)$ and turkey $3.10 \%(8 / 258)$. 
Comparison of participants with and without prior enrolment

The present analysis of the data also revealed that, turnout with prior enrolment for the training was $52.55 \%$ and without prior enrolment was $47.45 \%$. It was an interesting fact that, only for the training programme on sheep and goat farming, majority of the enrolled (79 /132) personnel had attended. But it was opposite in case of country chicken training, where majority of the trainees attended (153/250) were without prior enrolment.

\section{Adoption level of farmers in various enterprises}

This study showed that, out of 72 beneficiaries attended the training on dairy farming 07 had started the farm (10\%), 131farmers attended the training on sheep and Goat and 17 started the farms (13\%), out of 250 persons attended the training on country chicken farming 30 had started the farm (12\%), 19 attended the training on Japanese quail and 03 had started the farms (16\%). Although more number of people were found attracted towards native chicken farming, the percentage of adoption was found to be low. This might be due to the difficulties in getting the infrastructure in the immediate vicinity, in Ramanathapuram district. The adoption level among farmers with direct participation without prior enrolment were (06/17) $35 \%$ in sheep and goat, 23\% (7/30) in country chicken, $14 \%$ (01/07) in dairy farming. Overall the adoption level of farmers to start new farm was higher in the category of attending training with application (75\%) rather than direct participation without any prior enrolment (25\%). In broad perspective the adoption level to start new farm in this district was higher in young male participants of other community rather than SC/ST, with lesser education (Fig 7). The chi-square analysis of statistical interpretation on the various categories of sex, age, community, education, employment and monthly income generated among the group of farmers attended training with application form are well interpreted (Table 1 to 4).

The analysis of this impact study was similar in opinion to the study (Moris, 1991) and stated individual contact method with farmers before the training and preliminary discussion on farming practices make them to fill up the application and had very good response in attending training rather than direct participation in the training conducted.

It is well indicated that individual contact method was an ideal tool to convince farmers with face to face interaction and get counselled them very effectively rather than mass contact methods through advertisement in mobile apps, newspaper and TV Channels rendered them for direct participation.

A similar study of Hundal et al., (2016a; b) on the impact of training on knowledge level of goat farmers in punjab revealed that knowledge level of farmers towards goat farming is low and there is a significant improvement in their knowledge after attending five days training on various aspects of goat rearing traditionally as well as scientifically. Hence regular need-based training programme must be offered to update farmers with latest technology and research in goat farming.

As an extension effort, the impact study can be technically and practically useful for the perception level of this district towards attending training program and further adoption of new farms in this district. 


\begin{tabular}{|c|c|c|c|}
\hline \multicolumn{4}{|c|}{ Table.1 } \\
\hline & & \multicolumn{2}{|c|}{ Training attended (\%) } \\
\hline & & AP & DP \\
\hline \multirow[t]{2}{*}{ Sex** } & 1 & $89.14(230)$ & $88.84(207)$ \\
\hline & 2 & $14.73(38)$ & $11.16(26)$ \\
\hline \multicolumn{2}{|c|}{ Total } & $100.00(258)$ & $100.00(233)$ \\
\hline \multicolumn{2}{|c|}{ Chisquare } & \multicolumn{2}{|c|}{0.012} \\
\hline \multicolumn{2}{|c|}{ P value } & \multicolumn{2}{|c|}{0.914} \\
\hline \multicolumn{4}{|c|}{ Figures in parenthesis are counts } \\
\hline & & $* * \mathbf{P}<0.01$ & \\
\hline
\end{tabular}

AP - Applied and Participated

DP - Directly Participated

1 - Male; 2 - Female

\begin{tabular}{|c|c|c|c|}
\hline \multicolumn{3}{|c|}{ Table.2 Age Vs Training attended } \\
\hline \multirow{2}{*}{} & \multicolumn{2}{|c|}{ Training attended (\%) } \\
\cline { 2 - 3 } Age $^{* *}$ & 1 & AP & DP \\
& $23.26(60)$ & $40.34(94)$ \\
\hline & 2 & $57.36(148)$ & $45.49(106)$ \\
\hline 3 & $19.38(50)$ & $14.16(33)$ \\
\hline Total & $100.00(258)$ & $100.00(233)$ \\
\hline Chisquare & \multicolumn{2}{|c|}{16.70} \\
\hline P value & \multicolumn{2}{|c}{0.000} \\
\hline Figures in parenthesis are counts \\
\hline \multicolumn{3}{|c|}{$* *$ P<0.01 } \\
\hline
\end{tabular}

AP - Applied and Participated

DP - Directly Participated 1 - 18-30; 2 - 31-50; 3 - >50

\begin{tabular}{|c|c|c|c|}
\hline \multicolumn{4}{|c|}{ Table.3 Community Vs Training attended } \\
\hline & & \multicolumn{2}{|c|}{ Training attended (\%) } \\
\hline & & AP & DP \\
\hline \multirow{2}{*}{ Community* $_{*}^{*}$} & 1 & $15.89(41)$ & $18.45(43)$ \\
\hline & 2 & $84.10(217)$ & $81.55(190)$ \\
\hline \multicolumn{2}{|l|}{ Total } & $\begin{array}{c}100.00 \\
(258)\end{array}$ & $\begin{array}{c}100.00 \\
(233)\end{array}$ \\
\hline \multicolumn{2}{|l|}{ Chisquare } & \multicolumn{2}{|c|}{0.567} \\
\hline \multicolumn{2}{|l|}{ P value } & \multicolumn{2}{|c|}{0.451} \\
\hline \multicolumn{4}{|c|}{ Figures in parenthesis are counts } \\
\hline \multicolumn{4}{|c|}{$* * \mathbf{P}<0.01$} \\
\hline
\end{tabular}

AP - Applied and Participated DP - Directly Participated 1 - SC/ST; 2- Others

\begin{tabular}{|c|c|c|c|}
\hline \multicolumn{2}{|c|}{ Table.4 Education Vs Training attended } \\
\hline \multirow{2}{*}{ Education* } & \multicolumn{2}{|c|}{ Training attended (\%) } \\
\cline { 2 - 4 }$*$ & 1 & AP & DP \\
\cline { 2 - 4 } & 2 & $12.33(86)$ & $38.20(89)$ \\
\cline { 2 - 4 } & 3 & $13.18(34)$ & $15.02(35)$ \\
\hline & 4 & $40.70(105)$ & $33.48(78)$ \\
\hline Total & 100.00 & 100.00 \\
& $(258)$ & $(233)$ \\
\hline Chisquare & \multicolumn{3}{|c}{2.967} \\
\hline P value & \multicolumn{3}{|c}{0.397} \\
\hline \multicolumn{3}{|c|}{ Figures in parenthesis are counts } \\
\hline \multicolumn{3}{|c|}{$* *$ P<0.01 } \\
\hline
\end{tabular}

AP - Applied and Participated

DP - Directly Participated

1 - Upto SSLC; 2 - HSC; 3 - Diploma; 4 - Degree 
Fig.1 Relationship between training attended with application and sex

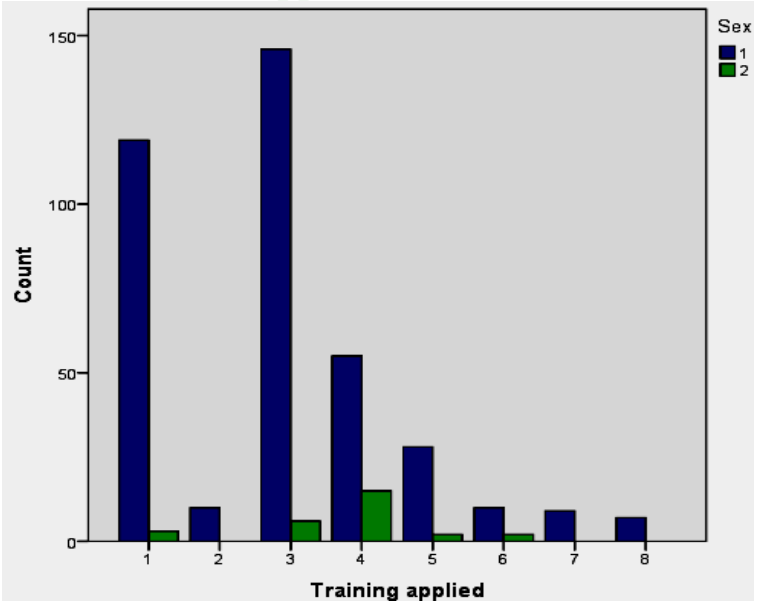

Fig.3 Relationship between training attended with application and community

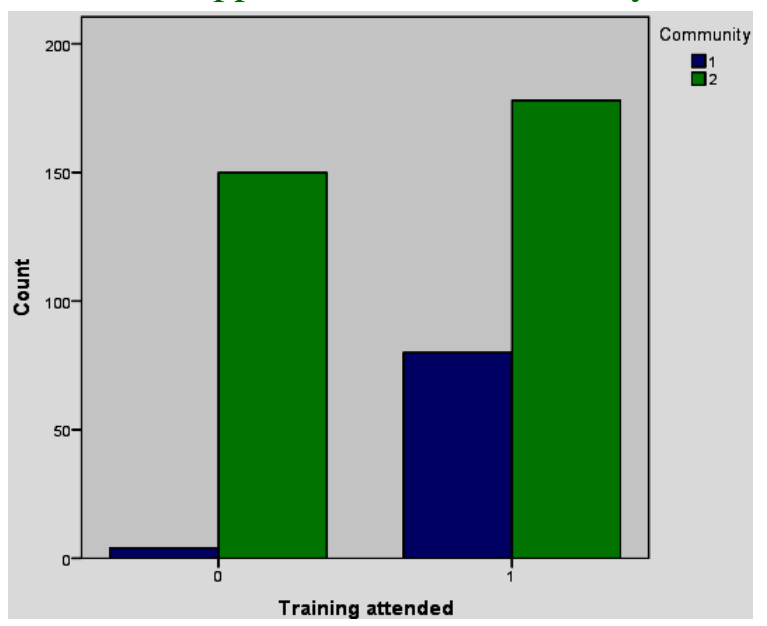

Fig.5 Relationship between training attended with application and employment

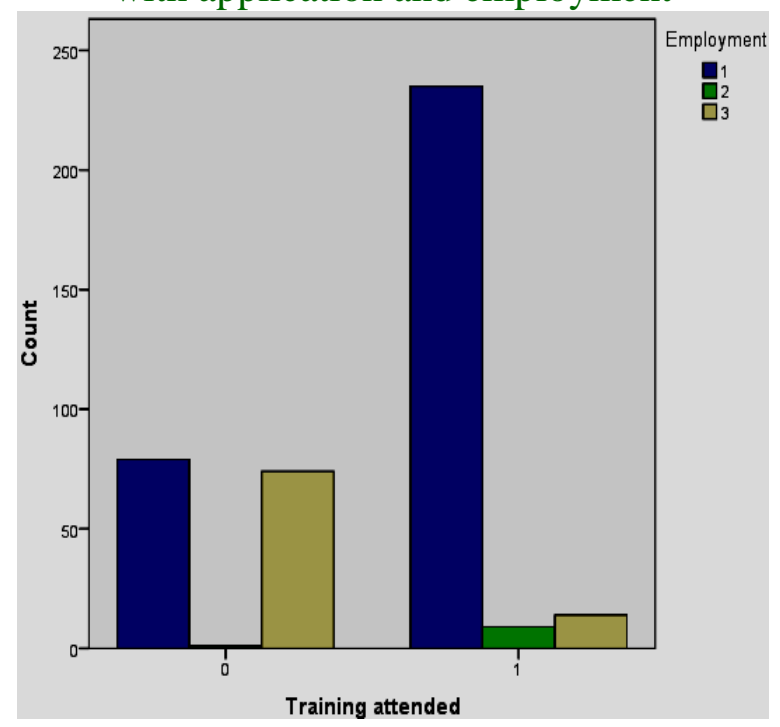

Fig.2 Relationship between training attended with application and age

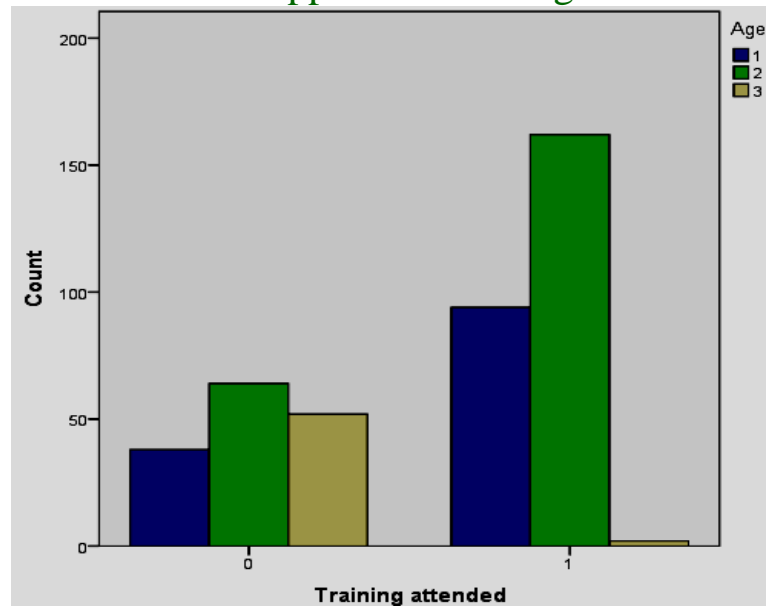

Fig.4 Relationship between training attended with application and education

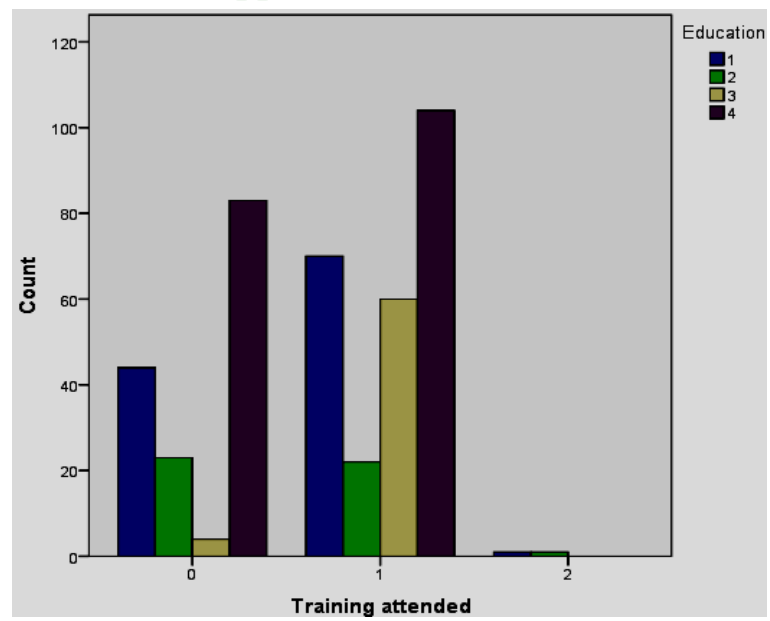

Fig.6 Relationship between training attended with application and monthly income

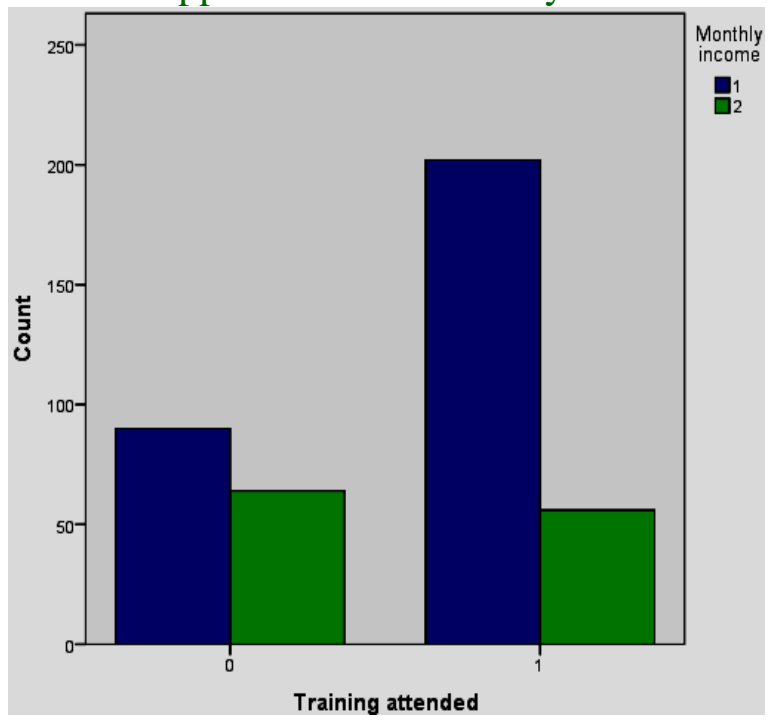


Fig 7. Farmers adoption level to start new farm

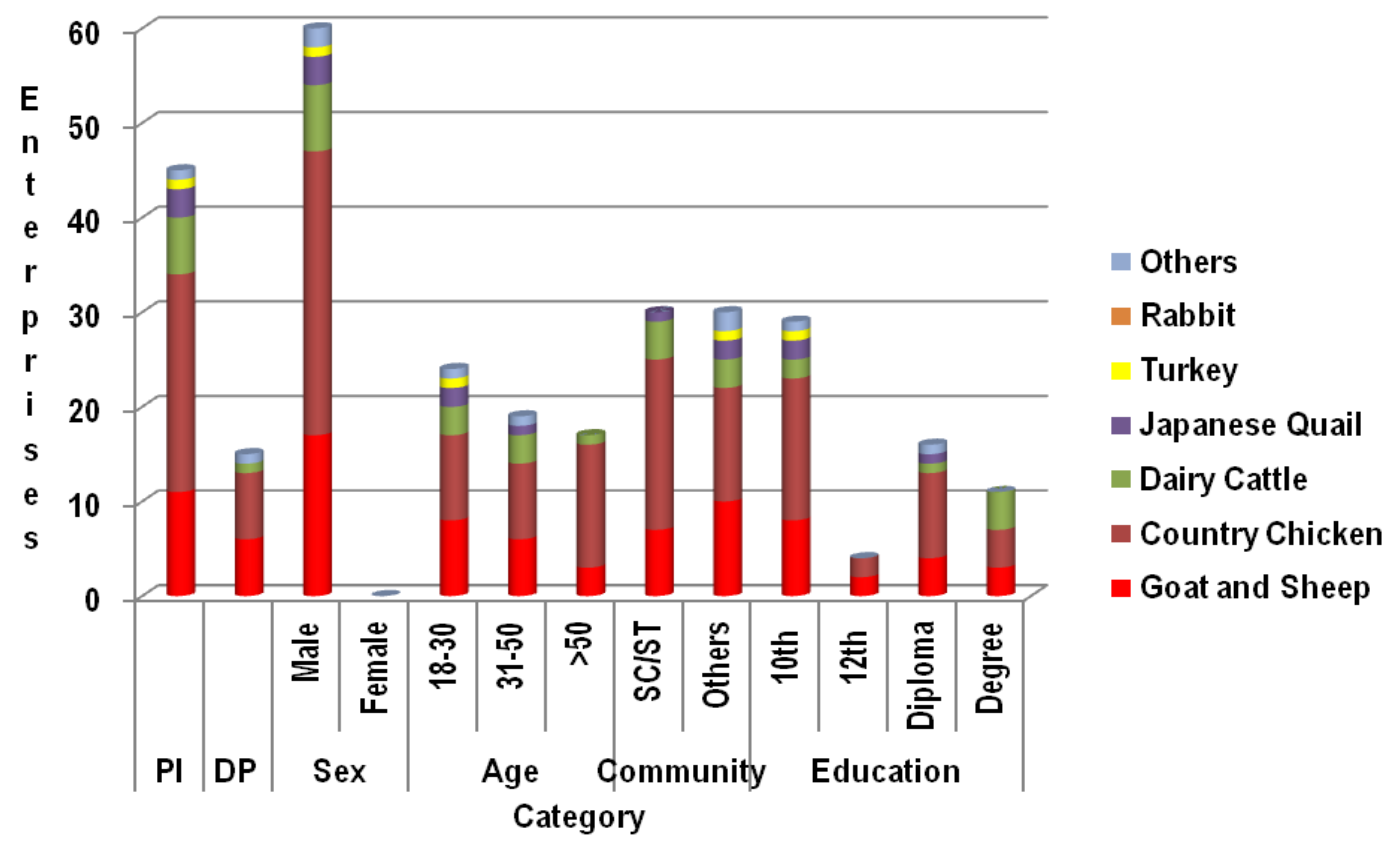

However, as a study, it was unable to correlate community, education status, employment and monthly income status category of participants attended training with the new farm adopted due of limited available data in the files and register. It was equally well important a follow up survey was highly essential and warranted for this study to incorporate the status of new farm started in the existing scenario. With all intervention the study could be useful and judge the adoption level of farming community of Ramanathapuram district and the limiting factors towards adoption strategies.

The study provided important insights on perception level of farmers to start new farm and the positive and negative feedback of this study, imparting the farmer mind towards adoption strategy. The salient features of this impact study revealed as follows:

There is a significant improvement in the knowledge of the participants after attending two days on-campus training on various farming enterprises.
The people attended the training programme with prior enrolment had started higher numbers of farms, indicated their continuous thirst and responsibility over their development.

Although 100\% attendance among female participants, the adoption rate was found to be low, indicated that decision making mainly vested with man in a family.

Older age group is efficient in attending oncampus training after submitting application. The lesser turn outs in direct participation might be due to ineffective reach of mass media and lack of using technologies.

Community imparts not much difference in this impact study, stating greater prevalence of community in this district leads to greater participation in the training.

Illiterate, lower education group (upto $10^{\text {th }}$ standard), degree holders showed good responsibility in attending training with and without prior enrolment. Higher school 
educators and diploma holders showed lesser inclination towards attending training.

Self-employed farmers showed very good response to attend training as compared to private sector personnel due to their busy time schedule. Although limited enrolment noticed in retired government personnel for the training, their response in attending training is $80 \%$ success.

People from higher income group had attended the training sincerely as compared to lower income strata.

Individual contact method before training is an ideal tool than mass contact method which will develop confidence and enhance perception level in farmers towards starting new farm.

The adoption level of farmers in attending training and starting new farm is higher in case of country chicken and sheep and goat farming.

The adoption level is poor in case of dairy farming, since huge initial investment and non-availability of green fodder are major limiting factor to start new farm in this district.

Overall male participants other than SC/ST community, younger age group and lesser educated group come forward in starting new farm after attending the training.

Participants with prior enrolment started more number of farms than direct participants.

This district is more in demand for country chicken training and sheep and goat training unlike other farming enterprises.

Data maintained for direct participants, follow up study of new farm started could be improved for further upliftment of this study to get fully utilized for this region.

Integrated consultative processes, with participation by all categories of stakeholders, are needed to improve ownership and implementation of interventions and to increase the impact of adoption level of farmers in Ramanathapuram District.

Thorough research of farmers' perceptions, information-seeking behaviours, knowledge and information needs are necessary to inform further development of extension methods.

\section{Acknowledgement}

The authors are very much thankful to Tamilnadu Veterinary and Animal Sciences University for providing this wonderful opportunity to bring out this data sources for the benefits and welfare of scientific community and farmers.

\section{References}

Abdullah, F.A., and Samah, B.A. 2013. Factors impinging farmers use of technology. Asian Social Science. 9(3): 120-124.

Adesina, A.A., and Baidu-Forson, J. 1995. Farmers' perceptions and adoption of new agricultural technology: Evidence from analysis in Burkina Faso and Guinea, West Africa. Agricultural Economics 13: 1-9.

Ahmed, M.D., 2015. Learning impact of farmer field schools of integrated croplivestock systems in Sinai Peninsula, Egypt. Annals of Agricultural Sciences 60(2): 289-296.

Campbell, D.A., 1999. Managing public sector extension organizations: Some critical issues. Paper presented at the 15 th Annual Meeting of the Association for International Agricultural and Extension Education. Trinidad and Tobago.

Davis, K., E. Nkonya, E. Kato, D.A. Mekonnen, 
M. Odendo, R. Mirro and Nkuba J. 2010. Impact of farmer field schools on agricultural productivity and poverty in East Africa. International Food Policy Research Institute. Washington, DC.

FAO., 2011. Success and Failures with Animal Nutrition and Technologies in Developing Countries. FAO animal production and health proceedings. In proceeding of FAO electronic conference, 1-30 September, 2010, Zimbabwe. pp.39-47.

Gedikoglu, H., and McCann, L. 2012. Adoption of win-win, environment-oriented, and profit-oriented practices among livestock farmers. Journal of Soil and Water Conservation. 67(3): 218-227.

Halakatti, S.V., C.M. Sajjan and Kamaraddi A. 2007. Empowerment of women through dairy training. Karnataka Journal of Agricultural Sciences 20(1): 89-92.

Hellin, J., 2012. Agricultural extension, collective action and innovation systems: Lessons on network brokering from Peru and Mexico. The Journal of Agricultural Education and Extension. 18(2): 141-159.

Hundal, J.S., U. Singh, N. Singh, S.K. Kansal and Bhatti J.S. 2016a. Impact of training on knowledge level of goat farmers in Punjab. Haryana Veterinarian. 55(1): 4749.

Hundal, J.S., U.S. Chahal, S.K. Kansal and Bhatti J.S. 2016b. Role of training in changing knowledge level among dairy farmers of Punjab. Haryana Veterinarian. 55(2): 220-223.

Kimaro, W.H., L. Mukandiwa and Mario E.Z.J.
(Eds.). 2010, July. Towards improving agricultural extension service delivery in the SADC region. Proceedings of the Workshop on Information Sharing among Extension Players in the SADC Region, Dar es Salaam, Tanzania.

Moris, J., 1991. Extension alternatives in tropical Africa. Overseas Development Institute. London, UK.

Pannel, D.J., G.R. Marshall, N. Barr, A. Curtis, F. Vanclay and Wilkinson R. 2006. Understanding and promoting adoption of conservation practices by rural land holders. Australian Journal of Experimental Agriculture 46(11): 14071424

Quddus, M.A., 2012. Adoption of dairy farming technologies by small farm holders: Practices and constraints: Bangladesh Journal of Animal Science. 41(2): 124135.

Quisumbing, A.R., and Pandolfelli, L. 2009. Promising approaches to address the needs of poor female farmers. Discussion Paper 00882. International Food Policy Research Institute (IFPRI). Washington, DC.

Snedecor, G.W., and Cochran, W.G. 1994. Statistical Methods. ( $8^{\text {th }}$ edn.) Oxford and IBH Publications, New Delhi.

Wambura, R., D. Acker and Mwasyete K. 2012. Extension systems in Tanzania: Identifying gaps in research (Background papers for collaborative research workshop). Retrieved from https:// docs.google.com/file/d/ 0B0k $\mathrm{cm}$ Raul GQQXZH dkk $3 \mathrm{~b}$ EZfNTg/edit? pli=1.

\section{How to cite this article:}

Vijayalingam, T.A., N.V. Rajesh, S. Ilavarasan, R. Venkataramanan and Ramasamy, D. 2019. A Study on the Factors Influencing the Rate of Learning and Adoption of Technologies by the Livestock Farmers of Ramanathapuram District, India. Int.J.Curr.Microbiol.App.Sci. 8(11): 790800. doi: https://doi.org/10.20546/ijcmas.2019.811.093 